\title{
Identity processes in smokers who want to quit smoking: A longitudinal interpretative phenomenological analysis
}

\section{Eline Meijer}

Leiden University, The Netherlands; Leiden University Medical Center, The Netherlands

\author{
Eleni Vangeli \\ London South Bank University, UK
}

\section{Winifred A Gebhardt}

Leiden University, The Netherlands

\section{Colette van Laar}

University of Leuven, Belgium

\begin{abstract}
The importance of identity in smoking cessation is increasingly becoming recognized by researchers. This study is the first in-depth longitudinal qualitative investigation of identity change processes among smokers who intend to quit. Participants' accounts of smoking, attempts to quit and sense of identity were explored over time to examine identity continuity and change. Ten smokers with a quit intention were interviewed three times, approximately I month apart, and approached for follow-up 2 years later. Data from 30 in-depth interviews were analyzed using the interpretative phenomenological analysis approach. Two themes of identity change processes are presented: "Identity transition makes it easier to quit" and "Identity conflict resolution is needed when quitting is unsuccessful or not attempted." Identity transition toward the identity of nonsmoker appeared to be facilitated by permeable identity boundaries, a continuous sense of identity, and a sense of mastery of quitting. Conflicted smoker identities were observed among participants who continued to smoke, along with
\end{abstract}

\section{Corresponding author:}

Eline Meijer, Department of Public Health and Primary Care, Leiden University Medical Center, PO Box 9600, 2300 RC Leiden, The Netherlands.

Email: e.meijer@lumc.nl 
barriers that appeared to prevent them from identifying with nonsmoking. Among these participants psychological (e.g. using downward comparisons with worse-off smokers) and behavioral strategies (e.g. hiding smoking from others) were seen that may serve to resolve identity conflict and protect a positive sense of identity. Our findings suggest that transition toward a nonsmoker identity may be necessary for successful quitting. Future research investigating ways to help smokers to perceive themselves increasingly as nonsmokers appears indicated.

\section{Keywords}

identity, identity change, interpretative phenomenological analysis, psychological processes, smoking cessation

Most smokers living in high-income countries want to quit smoking, but few succeed (Nationaal Expertisecentrum Tabaksontmoediging, 2015; U.S. Department of Health and Human Services, 2014). Quitting smoking may be more difficult when this contrasts with who individuals perceive themselves to be, that is, their identity. PRIME theory suggests that identity, which consists of "our mental representations of ourselves and the feelings attached to these," may be a key for behavior change (West, 2006). According to PRIME theory, identity affects the wants (e.g. anticipation of pleasure when smoking) and needs (e.g. anticipation of relief) that a smoker experiences in a specific moment, and the balance between these wants and needs subsequently directs behavior (e.g. a strong nonsmoker identity reduces the need for smoking, resulting in abstinence from smoking). Correspondingly, quantitative studies frequently report that smokers who identify more strongly with quitting or nonsmoking are more likely to quit or intend to quit, whereas smokers who identify more strongly with smoking are less likely to do so (e.g. Høie et al., 2010; Meijer et al., 2015, 2016, 2018b; Tombor et al., 2013, 2015). In addition, the (future) identities as nonsmoker and quitter appear more important for smoking cessation than the (current) identity as a smoker (Meijer et al., 2015, 2016, 2018 b), possibly because future identities in particular provide a source of motivation for behavior (Markus and Nurius, 1986).

Less is known about how smoker, quitter, and nonsmoker identities may change. Identity shift theory suggests that successful health behavior change (not restricted to smoking cessation) may facilitate identity change (Kearney and O'Sullivan, 2003). In line with this, a longitudinal study showed that identity (as smoker, quitter) and behavior are reciprocally related, such that identity impacts behavior and vice versa (Meijer et al., 2018b). In addition, another longitudinal study showed that smoker identities decrease over time, and quitter identities increase over time, among smokers and ex-smokers with higher (vs lower) socio-economic status (Meijer et al., 2017). This study also showed that smokers and ex-smokers who perceive stronger pro-quitting social norms develop stronger quitter self-identities over time. Finally, a longitudinal study among adolescents found that smoker identities increased over time among smokers who developed stronger "coping with negative emotions" motives for smoking (Hertel and Mermelstein, 2016). Although these findings are valuable, these quantitative studies provide only partial insight into the fine-grained psychological processes that enable identity change. The 
few in-depth qualitative studies that have been conducted with long-term ex-smokers suggest that identity change may involve a continuous process of transition with nonsmoking increasingly becoming part of identity (Brown, 1996; Luck and Beagan, 2015; Vangeli and West, 2012). Furthermore, change toward a nonsmoker identity may be enabled by continuous reaffirmation of the new identity (Brown, 1996), a transitional quitting identity (Vangeli and West, 2012), and learning of new behaviors that are unrelated to smoking (Luck and Beagan, 2015). Vangeli and West (2012) also highlight a dynamic and fluid identity following cessation, with participants oscillating between identification with smoking and nonsmoking. The "nonsmoker" identity appeared to gain strength over time for most possibly with increasing mastery over the "smoker" identity. Another study argued that the relapse of some women who had quit smoking during pregnancy was related to a lack of change away from the identity as a smoker ("nostalgia for the former self") (Bottorff et al., 2000).

Notably, cross-sectional work affords only retrospective exploration of identity change processes, rather than direct exploration of identity during the process of quitting. To our knowledge, this is the first longitudinal qualitative study to explore identity change processes among smokers. We investigated in-depth how smokers' sense of identity may change during the process of quitting, and what happens to their sense of identity if they cannot quit successfully. Ten smokers who intended to quit within 2 months were interviewed in-depth three times, and followed up via online survey after 2 years. An interpretative phenomenological analysis (IPA) (Smith et al., 2009) approach was taken to data-collection and data-analysis. IPA focuses on how individuals interpret and make sense of their experiences, and is, therefore, very well suited to exploration of identity change processes (Smith, 1999; Smith et al., 2009; Vangeli and West, 2012). The relatively small sample size is necessary to enable the idiographic focus of IPA and thus the development of insights that are contextually embedded (Smith et al., 2009).

\section{Method}

\section{Participants}

Ten daily smokers who intended to quit within 2 months were included (see Table 1 for demographic characteristics and smoking behavior). Five participants were recruited through a local newspaper advertisement, and five through the researchers' networks. One participant worked in the same institute as the first author, and one participant had worked there before the study commenced, but they neither collaborated with nor had a close relationship with the first author. Participant names are replaced with pseudonyms.

\section{Procedure}

Participants provided written informed consent and were interviewed by the first author in-depth three times in 2014 and 2015, approximately 1 month apart (T1, T2, and T3). We used semi-structured interviews that were very open to enable participants to raise areas of experience that they considered important to their experience of quitting (interview schedules are provided in Supplementary Materials A and B). If participants did not raise identity (e.g. as smoker or nonsmoker) spontaneously, the interviewer asked about 


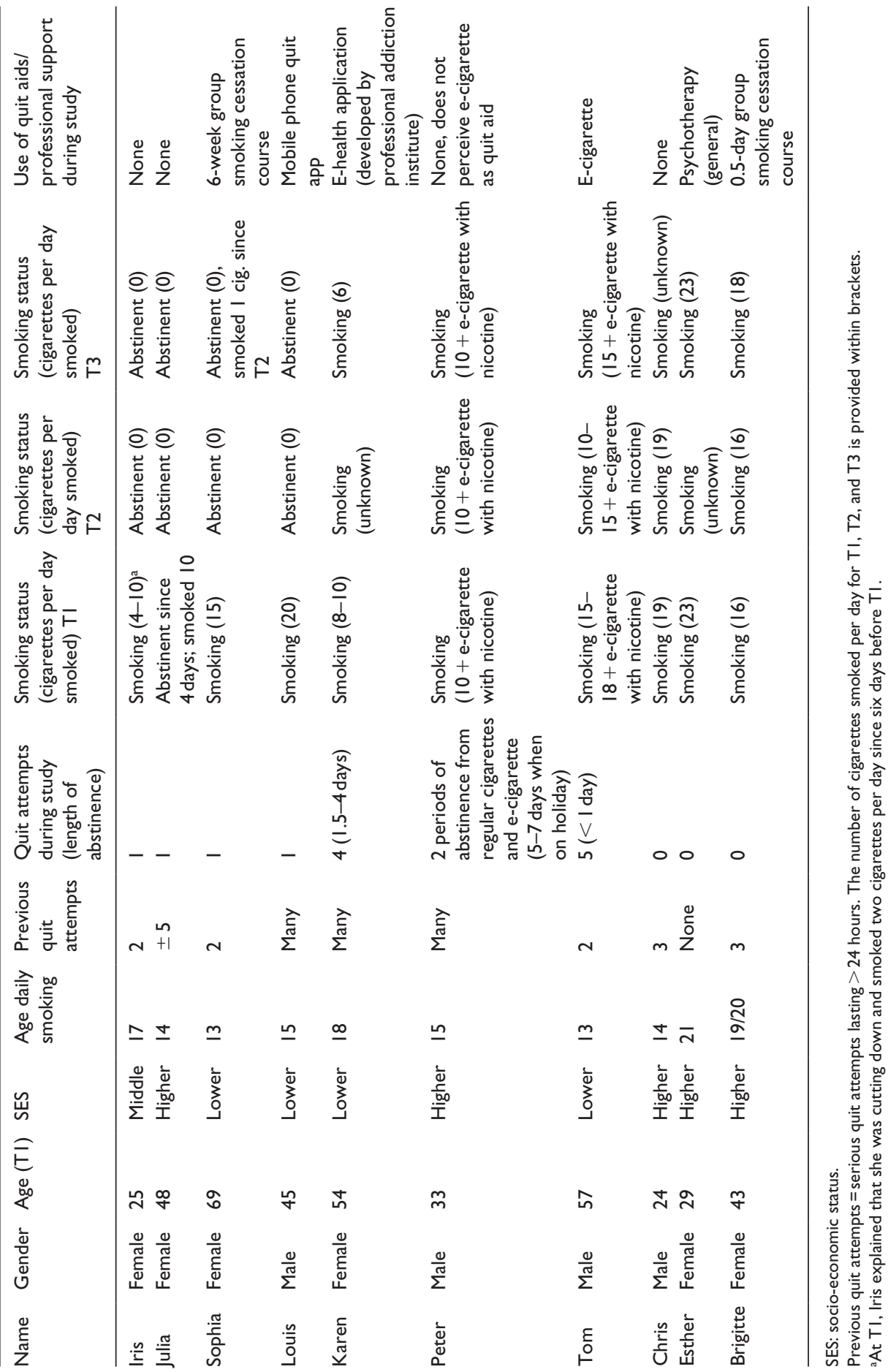


this toward the end of the interview to prevent shaping the rest of the interview. Questions about identity were "What are your thoughts about smoking/nonsmoking/quitting? Does it fit with who you are?" and "What are your thoughts about people who smoke/do not smoke/quit smoking?" The interviews lasted approximately 45 to 60 minutes. Lifelines were used to help participants organize their narratives and to make participants feel at ease (Wilson et al., 2007). Interviews were audio recorded and transcribed verbatim. Participants received $€ 50$ for participating. The Ethical Committee of Psychology of the first author's University approved the procedure. Participants were approached for a brief online follow-up questionnaire in October 2016 (T4) with questions about smoking status, quit attempts, and identity (i.e. "How do you see yourself in relation to smoking?"; full questionnaire provided in Supplementary Material C).

\section{Analysis}

Data were analyzed using IPA. IPA is grounded in phenomenology and is committed to understanding the participant's lived experience and meaning-making. A "double hermeneutic" is applied wherein the researcher interprets the participant's interpretations, thus privileging the participants' understandings while recognizing the central role of the researcher in the interpretation. Furthermore, IPA has an idiographic focus and aims for a detailed analysis of each case (Smith et al., 2009). The longitudinal analysis was conducted in accordance with the few published longitudinal IPA studies (Smith et al., 2016; Snelgrove et al., 2013; Spiers et al., 2015).

The analysis had the following steps: First, the transcript of a participant's first interview was read carefully. Second, initial (descriptive, linguistic, and conceptual) notes were taken. Third, notes were captured in emergent themes. Fourth, emergent themes for the first interview were grouped into superordinate themes, according to content similarity or connections between emergent themes. We continuously checked that our interpretations were grounded in the data by rereading transcripts, and listening to audiotapes when necessary. This was repeated for the same participant's second and third interview. After completing the separate analysis of each interview for one participant, we examined transitional themes over time to identify changes in a participant's sense of identity, potential mechanisms of identity change, and processes that may facilitate or hinder identity change. We then moved on to the next participant. As a final step, themes were compared across participants within two homogeneous subgroups (i.e. those who did and did not quit successfully). The analysis continued in the writing-up process. The analysis was performed primarily by the first author, who kept a reflexive log throughout data collection and analysis. For six randomly selected interviews, the first steps of the analysis (i.e. reading, noting, and emergent themes) were also performed by a second analyst, and independent interpretations were discussed to explore and develop themes. Interpretations were also regularly discussed with the second and third author to ensure that they were grounded in the data.

\section{Results}

During the study, four participants quit successfully (Iris, Julia, Sophia, and Louis), three participants attempted but were unsuccessful (Karen, Peter, and Tom), and three participants 
did not attempt to quit despite their intentions to do so (Chris, Esther, and Brigitte). Table 1 presents demographic characteristics, as well as participants' smoking behavior over the course of the interviews (T1 T3). Table 2 presents participants' smoking- and quitting-related identities over time, including example quotes. The analysis found two themes: (1) Identity change toward "nonsmoker" makes it easier to quit, and (2) Identity conflict resolution is needed when quitting is unsuccessful or not attempted. These identity dynamics are explored in Table 2.

\section{Identity change toward "nonsmoker" makes it easier to quit}

Four participants (Iris, Julia, Sophia, and Louis) quit smoking successfully and remained abstinent during the interview study. While Sophia and Louis presented a strong smoker identity across their interviews and struggled to adjust to nonsmoking, Iris and Julia adjusted to nonsmoking with relative ease. Although Sophia and Louis smoked more cigarettes than Iris and had been smoking for a longer period of time, Julia had been smoking a bit longer than Louis, and Julia, Sophia and Louis can all be considered "heavy smokers." Adjustment to nonsmoking appeared to be facilitated by a process of identity change, such that Iris and Julia identified more strongly with nonsmoking over time. This theme first explores how nonsmoking was integrated into identity over time in the accounts of Julia and Iris, and three mechanisms that appeared to facilitate this change via the subthemes of (1) Permeable identity boundaries, (2) Identity continuity in the absence of smoking, and (3) Mastery of quitting. The contrasting experiences of Sophia and Louis are also explored in relation to these themes.

Nonsmoking becomes a part of identity. Iris and Julia both showed identity change, such that over time nonsmoking became increasingly integrated in their identities (Table 2). At the first interview both described incongruence between their smoking and who they perceived themselves to be. For example, Julia said that she saw herself as a "nonsmoker who smokes," an identity that is inherently ambiguous. Her discomfort with this was clear as she explained what this meant to her: "For me, it's always been like, I do smoke, but I'm not okay with it." Although she did not yet see herself as a "nonsmoker," these self-definitions suggest a distancing away from identification with smoking. In line with this, others were surprised when they learned of her smoking, suggesting that they did not see her as a smoker either. For example, Julia explained,

People told me, like, because they never saw me smoke during the day, or the dentist, you know, they'd say well, that err [whispered] YOU? Are you serious? [continued in normal voice] That doesn't fit at all, or, that can’t possibly be, you know. (Julia, T1)

Still, although Iris and Julia did not identify with smoking, they also did not perceive themselves yet as nonsmokers. At the second interview, Iris and Julia had been abstinent for 5 and 32 days, respectively, with Iris having had several smoke-free periods since the first interview. Both described a recovery-related identity: Iris identified as an "ex-smoker in the rehab phase" and Julia as "a detoxed smoker." These suggest a process of transition to restore oneself to a more positive condition (e.g. restoration 


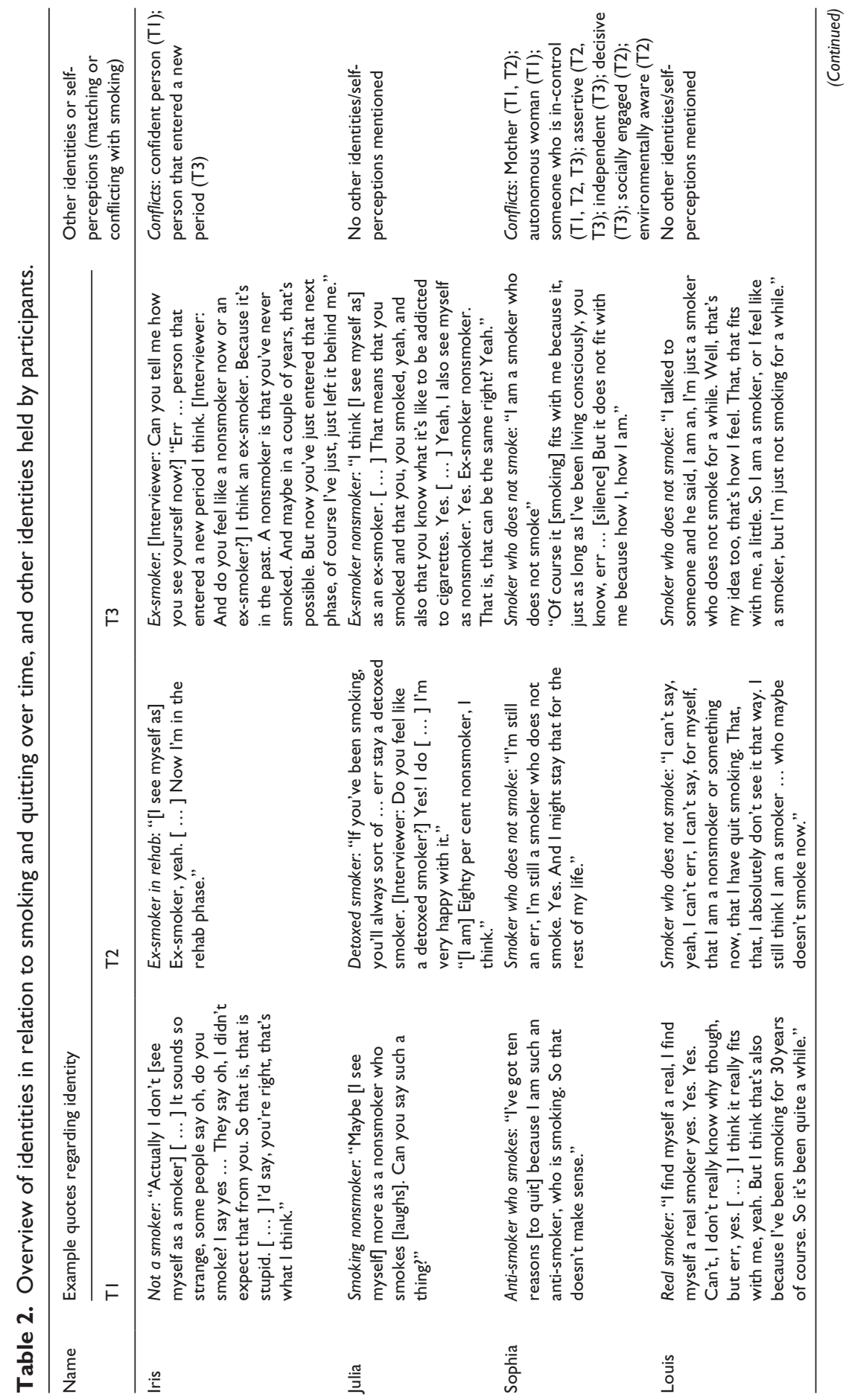




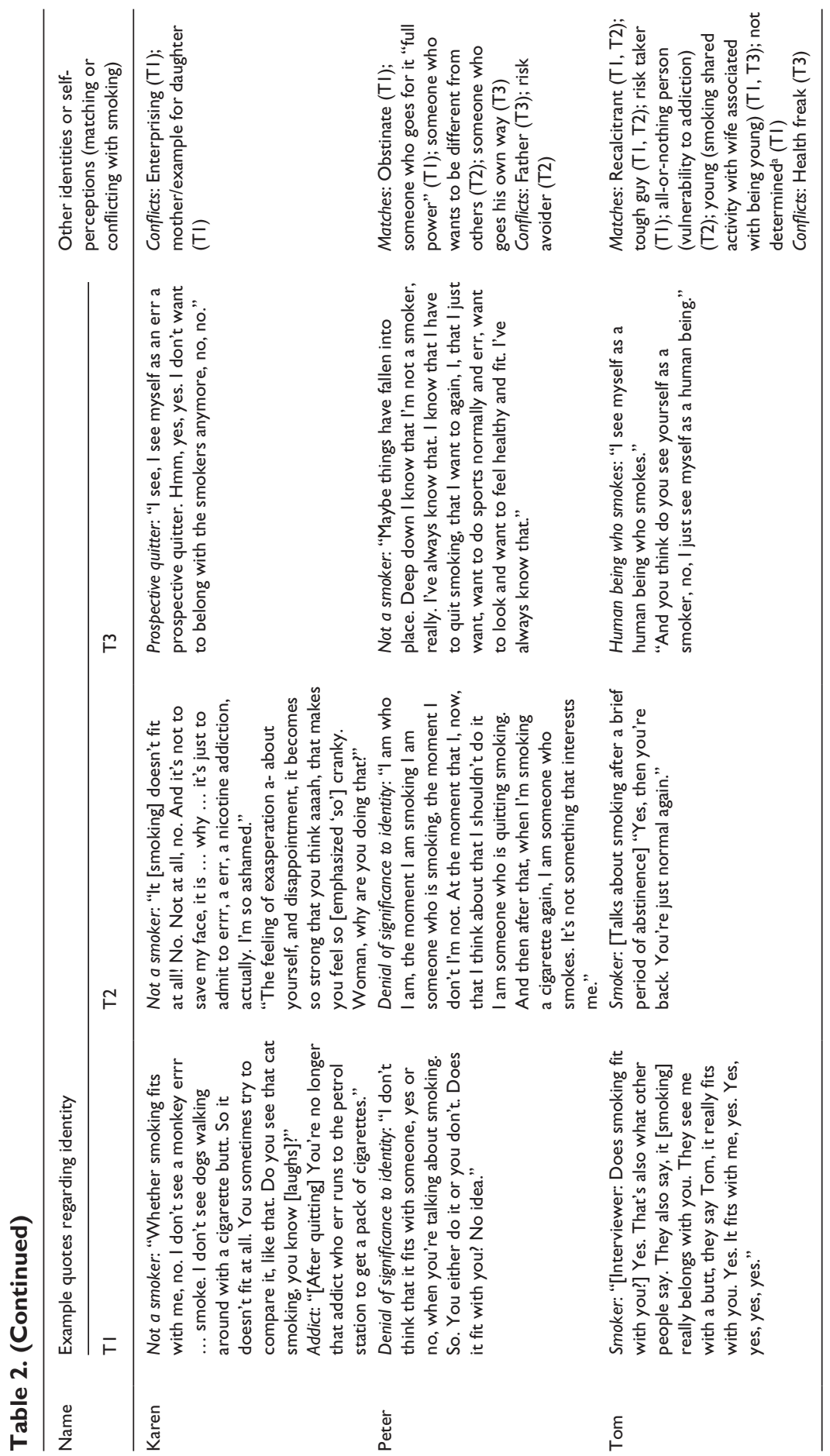




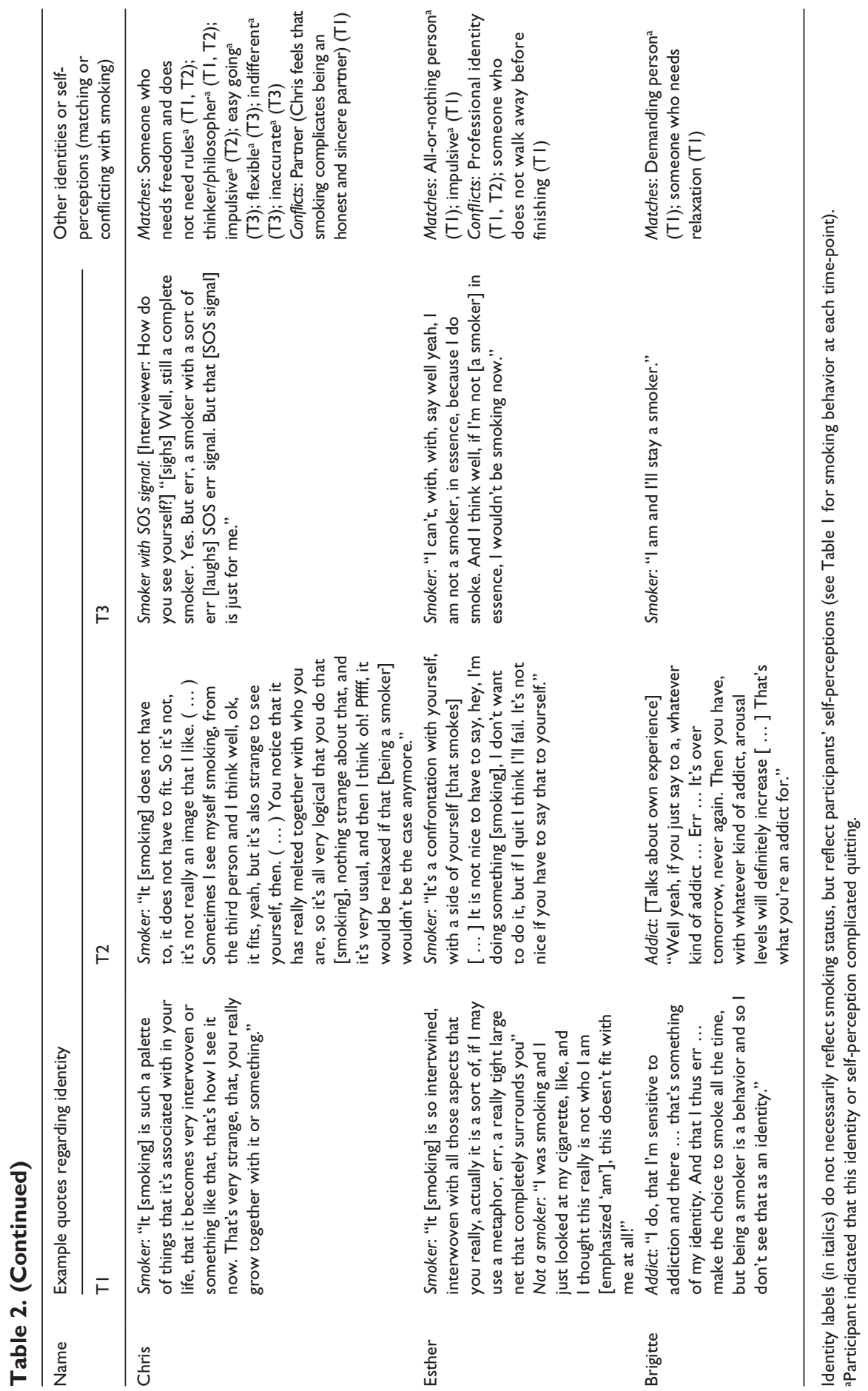


to health or removal of a toxic substance). Julia also described herself as an "eighty percent nonsmoker" (T2), indicating that the identities of detoxed smoker and nonsmoker co-existed.

Iris perceived the "ex-smoker in rehab" identity as temporary, and believed that she could become a nonsmoker with time:

Interviewer: When would you say that you're a nonsmoker?

Iris: Well, I think, in at least five years.

Interviewer: What would you need for that?

Iris: Yes err, well, yeah, I could also feel like a nonsmoker in a year, but that's, we'll have to see. Now I'm still in the re-, re- err rehab phase. Could be a year, or in five years, but also in a couple of months, depends on how quickly it goes. (Iris, T2)

Although Iris was unsure about how long it would take before she would become a nonsmoker, she perceived this to be transitional. Julia was more doubtful whether she would move beyond her "detoxed smoker" identity:

I think that once you've been smoking, you know, you always sort of ... err stay a detoxed smoker. I guess, that you, yeah, maybe, I hope that it, or in a year, that you think well, I can't imagine that I ever smoked. That it's just out of your system [ ... ] And it [abstinence] has just been a month, so it's not been that long [laughs]. (Julia, T2)

Whereas Julia believed that her (unchangeable) smoking history would "always" define her as a detoxed smoker, she also hoped that 1 day she would not even be able to picture herself smoking anymore. Her addition of "it's not been that long" suggests that she might move beyond her "detoxed smoker" identity in the near future ("in a year"). By the third interview, Iris and Julia (29 and 67 days abstinent, respectively) perceived themselves as ex-smokers. When Iris was asked how she saw herself, she said,

Iris: Err ... [a] person that entered a new period, I think.

Interviewer: And do you feel like a nonsmoker now or an ex-smoker?

Iris: I think an ex-smoker. Because it's in the past. A nonsmoker is that you've never smoked. And maybe in a couple of years, that's possible. But now you've just entered that next phase, of course I've just, just left it behind me. (Iris, T3)

As in the second interview Iris identified herself as an "ex-smoker," but instead of being in the "rehab phase," she had now entered "a new period" and "next phase," and left "it" behind her. Smoking was "in the past," she successfully moved away from her past smoker identity, and she marked this as a definitive change. Similarly, Julia presented herself as "ex-smoker nonsmoker" instead of "detoxed smoker" (Table 2), suggesting that she no longer perceived herself as someone in recovery. In line with these 
transitions in identity toward becoming a nonsmoker, Iris and Julia reported that quitting was relatively easy. For example, Julia said, "It has been going very well, yes, very well. Little to no urge [to smoke]" (T3).

The change observed in Iris' and Julia's identity involved a distancing away from a former smoker identity, and increasing accommodation of nonsmoking in their identities. Unlike Iris and Julia, Sophia and Louis did not show identity change, and this appeared to make quitting more difficult for them. Even though they no longer smoked, they essentially remained smokers in the way they viewed themselves as a "smoker who does not smoke" (Table 2).

Permeable identity boundaries enable identity change. The identity change processes observed for Iris and Julia appeared to be enabled by a perception of fluid, permeable boundaries between identities and behavior (e.g. smoking when "not a smoker" and "smoking nonsmoker"). As explored above, Iris initially defined being a nonsmoker as having "never smoked," but immediately added that becoming a nonsmoker is possible with time. Julia called herself an "ex-smoker/nonsmoker" in the third interview, and she suggested, "That can be the same, right?" Julia seemed to merge the two identities, which allowed her to identify as a nonsmoker, despite her history as a smoker. As such, Iris and Julia did not view being a smoker or nonsmoker as fixed identities with clear boundaries, but as dynamic identities with more fluid, permeable boundaries. This allowed them to navigate between identities, and to perceive themselves increasingly as people who no longer smoked and eventually as nonsmokers.

In contrast, Sophia and Louis had stable perceptions of the identities as smoker and nonsmoker. They both highlighted their smoking history as a reason for seeing themselves as smokers, for example,

I think it [smoking] really fits with me, yeah. But I think that's also because I've been smoking for 30 years of course. So it's been quite a while. (Louis, T1)

For Sophia and Louis, the possibility of identity transition to nonsmoker appeared out-of-reach. This is observed, for example, when Sophia talked about what it would be like to be a nonsmoker:

Well, I hope there will be a time ... I will only be a nonsmoker if it [smoking] no longer is a subject for me, so, that I for example just haven't thought about it for three days, and that I can just say no thanks, I don't smoke. Because I, I, I, I err, I don't have to tell anymore that I smoked in the past and that it was so difficult for me, that is ... behind me. But now it's just, the most important issue for me, you know. (Sophia, T2)

In the extract above, Sophia appeared to expect that she could only become a nonsmoker in the far future ("a time") and whether this happened at all appeared to be driven by "hope" rather than expectation. The requirements for becoming a nonsmoker are absolute (e.g. smoking should not come to mind at all for a period of time) and very different from her current situation where she is preoccupied with thoughts of smoking and still describes smoking as her "number one priority." This distinct and absolute nature of 
feelings and actions creates an impermeable boundary around the nonsmoker identity, making transition from smoker impossible without renouncing smoking completely.

Identity change is facilitated by a sense of identity continuity. Both Iris and Julia felt that quitting smoking allowed them to become the people that they essentially already perceived themselves to be when still smoking. In the second interview, Iris explained that "It [quitting] goes with it now. I still see the same person." As such, although her identity changed toward nonsmoker, she felt that she had essentially stayed the same. The importance of a continued sense of identity in the absence of smoking highlighted in the extract from Julia's account:

I'm very happy with it [being a detoxed smoker]. So it's not as if I'm thinking ooooh my life is err ... Like a friend of mine, life is not worth living, I've lost my best friend, and that that that, that's really what it's like for her ... I err, what do I have, that, that she became depressed like, what's the point of my life. [ ... ] Attributing it all to, err, well, if it has to be like this, if my life has to be this way, well I'd rather continue smoking and then err, then, with all the risks attached. (Julia, T2)

Julia was "very happy" being a detoxed smoker, and contrasted her own experiences with those of a friend who found it difficult to quit smoking. According to Julia, this friend felt like she had lost her "best friend" (cigarette), and lost her sense of meaning in life to the point of depression. Presenting the loss experienced by this friend highlights Julia's perception that life without smoking carries an existential threat ("what's the point of my life") for some. The contrasting of her friend's loss with her own positive experience of quitting suggests that Julia perceived identity continuity to be important.

Whereas a continued sense of identity following smoking cessation is seen in the accounts of Iris and Julia, for Sophia and Louis a sense of disconnection, or loss of identity, is observed. This can be seen, for example, in the second interview, when Sophia talks about the difficulty she had with quitting:

Sophia: I think well, Sophia, it's practically beneficial [to quit] and you just don't see it now err ... [silence] but it doesn't feel that way, I, rationally, I'm convincing myself, but it doesn't feel that way.

Interviewer: So how does it feel then?

Sophia: Well, like I told you. Err, err ... It's [smoking] a friend, you know, you are a p- an err, in a way you're amp- amputated [silence].

Interviewer: Part of you is-

Sophia: Part of what my life was like, I mean, coffee, I didn't smoke much just like this, but, or an, and, but I err, never [had] a cup of coffee without a cigarette. And here I am with that ... thing. (Sophia, T2)

Sophia had tried to convince herself that quitting was good, but to no avail, and instead describes a sense of loss both in terms of the experience of pleasure (i.e. drinking 
coffee now reduced to an unremarkable "thing") and to her sense of identity that had become incomplete via amputation. The comparison of smoking to a friend whose absence leads to a feeling of amputation invokes a sense of inconsolable loss, echoing the experience presented by Julia about her friend. At the end of the second interview when asked what smoking meant to her, Sophia elaborates on this friendship: "Smoking is an err ... a very dominant friend, err ... that I find it very difficult to say goodbye to, but what's actually a err, a err bothering thing, or person." This suggests that Sophia perceives the absence of smoking to be complex, as she paints a problematic relationship with smoking as the "dominant friend" and Sophia as the submissive friend with limited agency to end it. In addition, it points to a lack of control over smoking that Sophia may have experienced, as smoking is the "dominant friend" that she cannot leave, although she appears to want to do so. The significance of smoking to Sophia for a complete sense of identity highlighted when she describes how smoking just one cigarette between the second and third interview felt: "s- safe and familiar [ ... ] You're a little bit, who you were, let me put it like that. The amputation is gone."

Louis also struggled with his abstinence and felt different since quitting. This was most pronounced in the third interview, when he explains his psychological difficulties:

You only stay stuck in some sort of ... irrational anger. That really is, that's scary. I'm anxious about that. [ ... ] If someone would say well, this, cope with it for this one week and then err, it's over, promise, and then you'll be err yourself, because I really don't feel like myself right now. You know, like that. And, but in a week then, then it's again, all err, then err, your eyes will open and you'll see, you'll see the light and then you'll be, be the same person again. I would like that a lot. But no-one is going to say that. (Louis, T3)

In Louis' account, a sense of identity compromised by feelings of irrational anger, a loss of control over emotions, is observed. He did not feel like himself, and found himself in a dark and frightening place. In stark contrast to the initial transitional phase perceived by Julia and Iris, Louis saw himself as "only staying stuck" with this compromised identity. He longed to "be the same person again" that he was before quitting, but did not know when, and even if, he would regain his sense of identity. This sense of identity loss in the absence of smoking appeared to obstruct identity change in Sophia and Louis, whereas a continued sense of identity observed in Iris and Julia's accounts appeared to facilitate change.

Identity change is facilitated by a sense of mastery of quitting. The integration of nonsmoking in Iris' and Julia's identities also appeared to be facilitated by a sense of mastery in learning to live as nonsmokers. For example, in the third interview, Iris recalled how at work "You used to go outside to get some fresh air, to smoke. But you obviously don't do that anymore. So now I bring a book, or I surf the internet." Her use of the personal pronoun "you" in the plural and second person when recollecting her smoking behavior, and moving to the singular and first person "I" to describe her behavior now, may reflect a distancing from the smoker identity. Both Iris and Julia felt proud of their progress with quitting, and gained self-confidence from this achievement. In the third interview, for example, after achieving 2 months abstinence, Julia explained: “I'm very proud of myself. It [smoking] is something that I don't need anymore, it's not necessary anymore. 
So it's some sort of achievement." This sense of pride and mastery appeared to be related to her new identity as a nonsmoker. For example, when Julia ate out with three smokers as "the only nonsmoker in the group," she felt proud that she did not have to "stand outside like that [to smoke]." This sense of mastery is in stark contrast to her perception of current smokers:

Interviewer: What comes to mind, when you think of smokers?

Julia: Now I think, it's quite bothering. It [smoking] just never stops. It's not like err, a choice of, a cigarette. It's a chain of one cigarette butt after the other. You know, it just never stops. It's like a train that just keeps going. (Julia, T3)

The metaphor of a running train that never stops positions smokers as without control over their smoking behavior, with a sense of powerlessness through the absence of choice to smoke and consequent "chain" smoking. This sense of powerlessness was supported in Julia's reduction of smoking to the waste material (i.e. cigarette butt) that serves to strip smoking from positive value and thus reason to smoke.

In the third interview, when Iris was asked what smoking now meant to her, she used a metaphor to describe how quitting smoking made her feel free:

It [smoking] is a closed period in my life. And that, you carry it with you, further. It [smoking] wears off more and more. And then, that, you spread your wings and you are completely loose, free again. (Iris, T3)

Iris explained that she struggled with low self-confidence in the past, and she felt that smoking was tied to this. In her account above, she describes this period of her life as closed, and her sense of mastery of quitting appeared to allow her to become a more confident (nonsmoking) person. Sophia and Louis however, did not gain confidence in quitting, but both described quitting as a "battle" in the third interview, indicating that quitting was a sustained fight and required a high level of effort to maintain. In addition, they both remained strongly attracted to smoking. For example, in the third interview Louis said that "everything within me screams [sighs] smoking." The difficulty that they experienced with nonsmoking possibly made it more difficult to imagine themselves as nonsmokers or transition toward this.

\section{Identity conflict resolution is needed when quitting is unsuccessful or not attempted}

Identity issues were also observed in the six participants who did not quit successfully (Table 1). In line with their intentions to quit smoking, most participants perceived the behavior of smoking as conflicting with other identities (e.g. father) and self-perceptions (e.g. risk-avoiding), Table 2. For example, Esther (T1, smoker) perceived smoking as conflicting with her professional role: "Actually it [smoking] does not fit with me at all ... And, and my job, and, and ... Things that I find important.” However, although being a smoker appeared to be a negative identity that conflicted with other aspects of who they 
perceived themselves to be, at the same time some participants also perceived smoking as matching with other aspects of who they are (e.g. obstinate).

One way to resolve identity conflict between being a smoker and other identities/selfperceptions may be to move away from being a smoker and toward becoming a nonsmoker (and quit smoking). However, these six participants all found it difficult to picture themselves as nonsmokers (like Sophia and Louis). That is, although most of these participants experienced identity conflicts, they also lacked a positive future identity as a nonsmoker that could serve as a goal in their quitting process. In the first subtheme below two examples of psychological barriers observed that complicated identification with a future nonsmoking identity are presented. In the second subtheme, we will explore the psychological and behavioral strategies that participants used that may serve to protect a positive sense of identity in the face of their identity conflict and difficulty to quit.

Barriers to identification with a positive future nonsmoker identity. Several barriers were observed that appeared to prevent the participants who did not quit successfully, or did not attempt to quit, from identifying with nonsmoking. The two barriers that were observed in the most participants are presented in Table 3 for other barriers.

Perceptions of quitting as not fitting with certain identity aspects. Chris, Esther, and Brigitte perceived aspects of whom, or how they perceived themselves to make quitting more difficult. For example, Chris said, "I am such a person who is so, I like to philosophize, you know. And sometimes I wonder whether that could very, very much, obstruct my quitting" (T2, smoker).

Expectations of feeling incomplete without smoking. Esther, Chris, and Tom expected to feel incomplete without smoking and described a sense of loss of identity, or of pleasure and purpose in life that they associated with quitting smoking (similar to Sophia and Louis). For example, this can be seen in Chris's account below of his previous quit attempts:

It feels just like there's sort of err, you know, like, you're the bathroom floor and it, and it, and the err, bathmat with suckers is being pulled away from you, that's what is sort of feels like, that's very strange. Because it, yeah, it's very much err, linked to everything you do. (Chris, T1)

Here, Chris presents his experience of quitting smoking as the separation of two objects that are conglutinated together (via bathmat suckers) encompassing all areas of his life. This creates an image of an aggressive force required to pull smoking away from him and suggests an immediate and strong sense of loss at its removal. The passive tone that Chris uses to describe this process (it "is being pulled away") also indicates a sense of lack of control over smoking.

Strategies to protect a positive sense of identity when being unable to quit. All six smokers who were unable to quit successfully, or did not attempt to quit, were seen to use strategies to protect a positive sense of identity. Psychological strategies observed were downward comparisons, self-affirmation, avoidance, and denial. In addition, two behavioral 


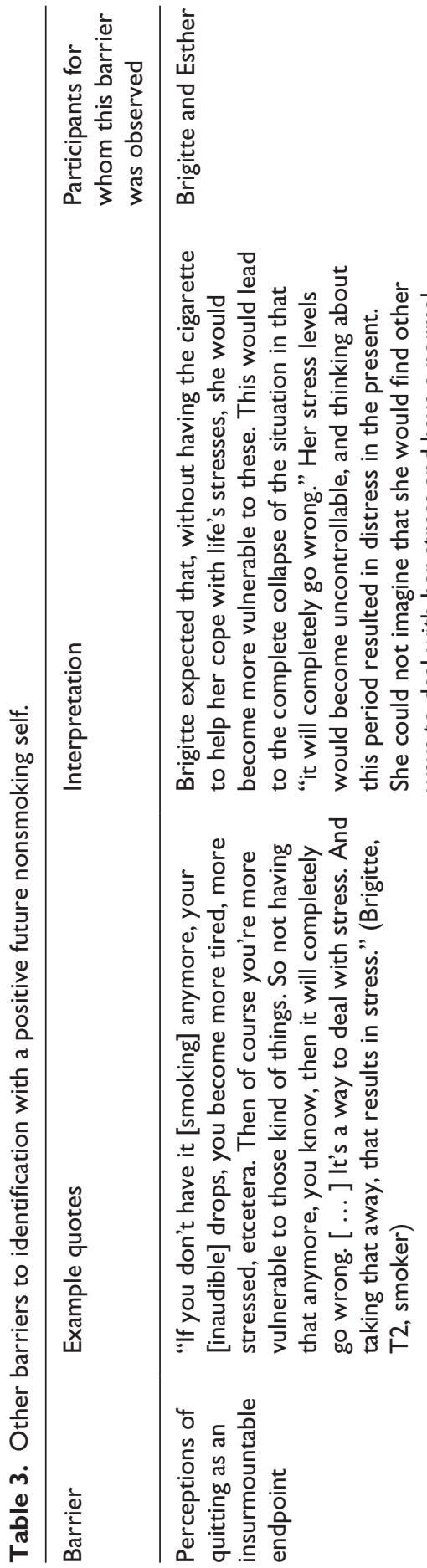

$\frac{\sqrt{\frac{1}{\pi}}}{\frac{0}{\sqrt{n}}}$

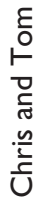

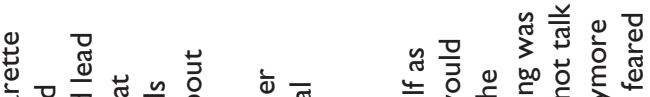

这.

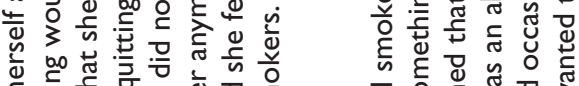
ब.

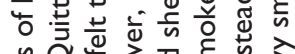

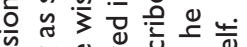
突 ठั

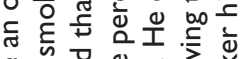
๑ั ฮั

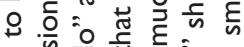

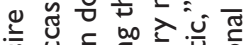

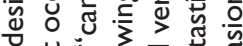

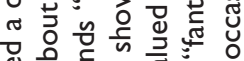

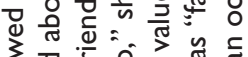

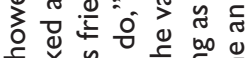

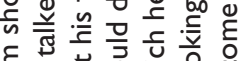
○े

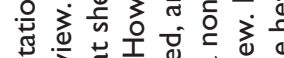

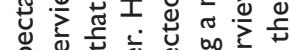

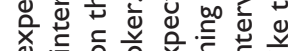
ه 议 入.

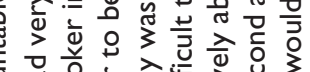
它

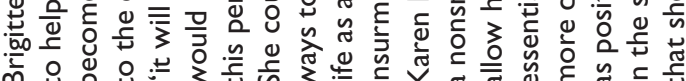

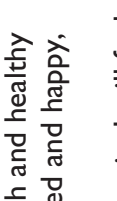

ब

पू

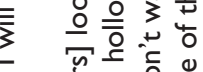

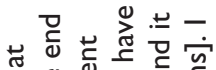

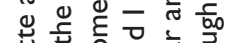

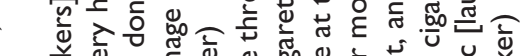

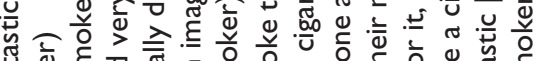

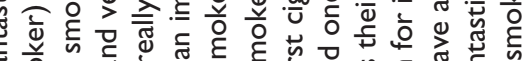

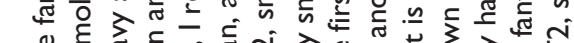
ฮู

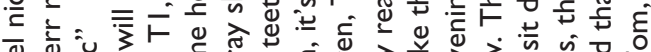

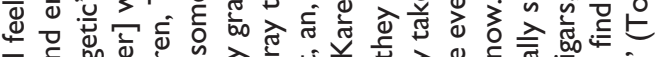

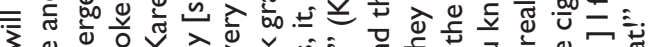
了ข 003

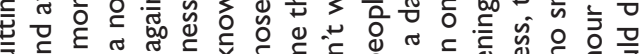
可的

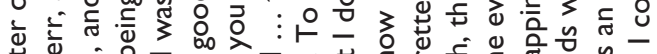

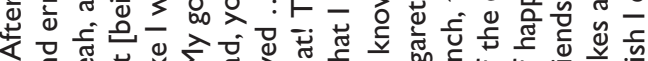

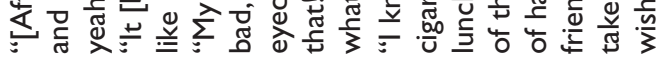

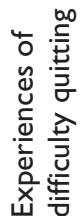

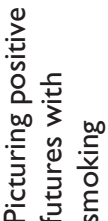


strategies, hiding smoking to resolve social conflict and independence strategies, were observed. These are discussed below.

Psychological strategies. Esther, Peter, and Tom made downward comparisons with other smokers, by pointing out that they themselves were more decent or socially considerate (Esther) or less "fat" (Peter) than other smokers. Similarly, Tom had lost a friend who died from lung cancer and described his funeral:

Everyone was smoking. And the guy was lying on his stretcher two meters away from us [talks in disapproving voice]. Isn't that bizarre? [ ... ] And we're joking and talking about his life, and no one talks about smoking! [ ... ] It keeps me occupied, yes, yes, yes. And smoking too, it keeps me occupied, keeps, and err, I am not a thoughtless smoker, I have, a friend of mine, and I can sit and talk with her, and she ... smokes, and walks to the dish washer and smokes indoors, and smokes again and very much too, maybe even 2 packs a day ... She always has a cigarette in her face. (Tom, T3)

Following Tom's surprise and disapproval at the continued smoking of the funeral guests, of which he was one, he immediately presents a new smoker identity ("not a thoughtless smoker") that elevates his status compared with other smokers who do not exercise thought. His description of these smokers in a derogatory manner as thoughtless and his example of a friend who "always has a cigarette in her face" probably made him feel better about himself as a smoker.

Chris and Peter appeared to use self-affirmation strategies (i.e. focusing on one's positive characteristics) to protect a positive sense of identity. For example, in the first interview Peter talked about continuing smokers, and his own continued smoking, as follows:

Peter: I can't imagine that there's anyone who doesn't want to quit smoking, who does smoke. I just don't believe that. So that means that [if you are smoking] you can't quit smoking, in my opinion. So you don't have stamina, or endurance.

Interviewer: Right. Does that also apply to yourself?

Peter: Yes, definitely. Otherwise I would have quit smoking. Right? [laughs] [ ... ]

Interviewer: What's that like, thinking about that?

Peter: Tomorrow is another day? Yes. Nothing more, nothing less. I don't care so much, personally. I do so many other things, which I do well, and with which I have endurance and which I finish and whatever. And one thing's not. Yes. Okay, so I'm not a hundred per cent, but I got far, with having my life on track. (Peter, T1)

Peter perceived his continued smoking to indicate that he lacked stamina, but did not want to elaborate on this. He downplayed the importance of lacking stamina ("tomorrow is another day") and instead focused on everything that he succeeded in. Notably, although Peter presented quitting smoking as trivial here, he said later "If I would quit and stick with it, it [life] will be more complete. [ ... ] I might desire to have everything 
in my life on track" (T1). This indicates that quitting smoking was a key component of getting his life on track. Focusing on his successes allowed him to balance the negative impact of his continued smoking on his identity, and to perceive himself positively.

Some participants showed avoidance or denial of a smoker identity. For example, in Esther said that "It's a confrontation with yourself. With a side of yourself [that smokes]. [ ... ] So preferably, you always try to ... push it to the background" (T2). Esther acknowledged that "a side" of her was a smoker, but she avoided thinking about this negative identity. Brigitte and Peter denied that smoking and nonsmoking were in any way relevant for how they perceived themselves. This allowed removal (or reduction) of the identity threat associated with continued smoking. For example, in the first interview Brigitte said,

I don't feel like it [smoking] is a part of me, who I am ... No. It's part of what I do, but that doesn't necessarily mean that it's a fixed part of who I am. (Brigitte, T1)

In the extract above, Brigitte perceives that having a smoker identity meant that smoking was a stable part of her, something she did not seem to want. Similarly, in the first interview Peter presents smoking as a simple consumer choice like eating pasta as he asks: "Does eating pasta fit with you? That's the same question." However, between the second and third interview, Peter had reflected on his life and realized that he was unhappy with his smoking and lifestyle to reveal a sense of identity conflict:

Maybe things have fallen into place. Deep down I know that I'm not a smoker, really, I've always known that. I know that I have to quit smoking, that I want to again, I, that I just want, want to do sports normally and err, want to look and want to feel healthy and fit. I've always known that. (Peter, T3)

In the extract above, Peter admitted that his current smoking behavior had "always" conflicted with his sense of who he truly was. He experienced this realization positively ("things falling into place"), and a strong increase in his motivation to quit was observed. Peter now referred to quitting smoking as something that he "wanted" to do, whereas before quitting had been something that he "had to" do. His earlier denial of the significance of smoking to his identity may have served to reduce this identity conflict.

Behavioral strategies. Participants described employing behavioral strategies to protect themselves from the negative consequences of smoking. Esther and Karen attempted to avoid the social consequences by hiding their smoking, and Brigitte employed strategies to feel more independent. Esther felt that smoking conflicted with her professional identity, and believed that her colleagues would think less of her if they would see her smoking. Esther described how she would "sneak around" and "crawl away, like an ashamed dog," "never with my head held high" (T3) if she went outside to smoke, to prevent colleagues from noticing her need to smoke and judging her negatively. Using the dehumanized metaphor of an "ashamed dog crawling away" possibly reflects a fear of being judged as being without human agency, because of her "horrible addiction" to cigarettes, and succumbing to primal urges of an intelligent animal (i.e. an animal with an awareness of expected behavior, capable of feeling shame). 
Table 4. Follow-up smoking status, quit attempts and identity.

\begin{tabular}{|c|c|c|c|c|}
\hline Name & $\begin{array}{l}\text { Months to } \\
\text { follow-up }\end{array}$ & $\begin{array}{l}\text { Smoking status } \\
\text { (\#cigarettes p/day) }\end{array}$ & $\begin{array}{l}\text { Duration and recency } \\
\text { most recent quit } \\
\text { attempt since } \mathrm{T} 3\end{array}$ & Self-label \\
\hline Iris & 19 & Abstinent & Abstinent since $\mathrm{T} 3$ & "Ex-smoker" \\
\hline Julia & 18 & Abstinent & Abstinent since $\mathrm{T} 3$ & $\begin{array}{l}\text { "Nonsmoker who used to } \\
\text { smoke" }\end{array}$ \\
\hline Sophia & 19 & Smoking (10) & No quit attempt & $\begin{array}{l}\text { "Someone for whom } \\
\text { relapse looms time and } \\
\text { time again" }\end{array}$ \\
\hline Louis & 18 & Smoking (20) & $\begin{array}{l}3 \text { weeks ( } 17 \text { months } \\
\text { ago) }\end{array}$ & "Fine" \\
\hline Karen & 18 & Smoking (6) & 3 days ( 16 days ago) & "A nonsmoker" \\
\hline Tom & 19 & Smoking (15-20) & $\begin{array}{l}\text { No quit attempt } \\
\text { lasting }>24 \text { hours }\end{array}$ & $\begin{array}{l}\text { "Someone who enjoys } \\
\text { it but does not have the } \\
\text { strength to quit" }\end{array}$ \\
\hline Chris & 18 & Smoking (20) & I. 5 day ( 237 days ago) & $\begin{array}{l}\text { "Someone who is addicted } \\
\text { and is captured in the } \\
\text { addiction" }\end{array}$ \\
\hline Esther & 28 & Smoking (20) & No quit attempt & "An addict" \\
\hline Brigitte & 28 & Smoking (20) & No quit attempt & $\begin{array}{l}\text { "Someone who seems to } \\
\text { need a cigarette to be able } \\
\text { to concentrate" }\end{array}$ \\
\hline
\end{tabular}

No follow-up data was available for Peter.

Brigitte attempted to increase her sense of control over smoking by deliberately buying her cigarettes separately for each day. She described this as "my way to control it [smoking]," although at the same time she recognized this to be an "excuse" and a way of "fooling herself" (T3).

\section{Follow-up survey (T4)}

All participants except Peter completed the follow-up survey on average 20 months after T3 (Table 4). While four participants had successfully quit at T3 (i.e. Iris, Julia, Sophia and Louis) only Julia and Iris - who in their interview accounts demonstrated identity change toward a nonsmoker identity - reported continuous abstinence at follow-up. Sophia and Louis however-who presented a resistant smoker identity in their interviews - had relapsed and smoked 20 and 10 cigarettes per day, respectively. At followup, Iris labeled herself as an "ex-smoker," and Julia as a "nonsmoker who used to smoke." Instead, Sophia labeled herself in terms of inevitable relapse, "someone for whom relapse looms time and time again," and Louis refrained from defining himself in terms of smoking and nonsmoking altogether.

None of the participants who were smokers at T3 were abstinent at follow-up (followup data was unavailable for Peter). Most still perceived themselves in terms of smoking and addiction. Karen, however, perceived herself as a nonsmoker at follow-up, although 
she had not (yet) quit successfully. She had attempted to quit very recently, suggesting that she tried to behave in line with her nonsmoker identity (see Tables 2 and 3 for Karen's identity processes in the interviews).

\section{Discussion}

This is the first longitudinal qualitative study that explores identity change processes in quitting smoking. Two themes in relation to identity were presented: (1) Identity change toward "nonsmoker" makes it easier to quit, and (2) Identity conflict resolution is needed when quitting is unsuccessful or not attempted. Of the four smokers who quit successfully over the course of the interviews, identity change toward nonsmoker was indicated in half, and a "smoker who does not smoke" identity in the other half. Importantly, quitting appeared much easier for those who increasingly perceived themselves as nonsmokers. Similarly, Vangeli and West (2012) suggested that a lack of identity change toward nonsmoker made abstinence more difficult for some. The "smoker who does not smoke" identity was also observed in an ethnographic study among smoking cessation group participants (Nachtigal and Kidron, 2015), but was considered a means to resist temptations to smoke and empower the nonsmoker identity, something our results do not seem to support. Extending previous work, follow-up results from the current study corresponded with the identity processes observed in the interviews, as only those for whom identity change was observed had gained long-term abstinence. The current findings thus suggest that nonsmoking needs to become incorporated in ex-smokers' identity in order to reach stable abstinence.

Results suggest that perceptions of permeable identity boundaries, a sense of identity continuity and a sense of mastery of quitting enabled identity change in the two participants who increasingly identified with nonsmoking. The perception of smoker and nonsmoker identities as flexible (e.g. smoking nonsmoker) appeared to ease navigation between identities. Permeable identity boundaries were possibly supported by a transitional recovery identity (e.g. "rehab phase" or "detoxed smoker"). This permeability relates to the conceptualization of identities as nonsmoker and smoker as fluid, as was proposed by Vangeli and West (2012) who found that ex-smokers oscillated between nonsmoker and smoker identities.

Furthermore, identity change in these two participants seemed to be facilitated by a sense of identity continuity: they essentially stayed the same person in the process of change. In contrast, the two participants who did not show identity change and relapsed by follow-up experienced a sense of loss of identity without smoking. Similar experiences were reported in other studies, describing a "voided self" without smoking (Nachtigal and Kidron, 2015) or a sense of loss that resembled "bereavement" (Vangeli and West, 2012). Importantly, a lower sense of identity continuity relates to worse psychological well-being (Sokol and Serper, 2016), and follow-up results of the current study suggest that it may be a risk for relapse (cf. Bottorff et al., 2000). Identity change also appeared to be facilitated by a sense of mastery of quitting. This resonates with observations by Vangeli and West (2012) that identity transition from smoker to nonsmoker was facilitated by "the accumulation of experience in mastery over urges to smoke" (p. 178) (see also Luck and Beagan, 2015). It also corresponds with the proposition of identity shift theory that identity change 
is facilitated by successful behavior change (Kearney and O'Sullivan, 2003), which may be reflected in sense of mastery, and with a previous study showing that quitting behavior may impact smoker and quitter identity (Meijer et al., 2018b). More research is needed to further disentangle the direction of relations between identity change and behavior change.

Identity also played a role in the six participants who were unsuccessful in quitting during the study. For most of them, being a smoker conflicted with other identity aspects, such that the identity as smoker was negative. Although identity change toward nonsmoker may be a possible way to resolve such conflict, for various reasons, all had difficulty picturing themselves as nonsmokers. The lack of a nonsmoker identity also seemed to impair smoking cessation. None of these participants had quit successfully at follow-up, and most still perceived themselves in terms of smoking and addiction. This corresponds with previous work, suggesting that smokers need a strong nonsmoker identity, rather than a weak smoker identity, in order to quit smoking (Meijer et al., 2015, 2016, 2018b).

The difficulty with quitting experienced by these continuing smokers thus appeared to prevent resolution of identity conflict, and thereby to threaten a positive sense of identity. Several psychological and behavioral strategies were observed that might protect a positive identity in the face of (perceived) inability to quit. Participants used downward comparisons with worse-off smokers or self-affirmation (i.e. focusing on positive experiences instead of difficulty quitting), avoided thinking about their negative identity, and denied the impact of smoking on identity. In addition, some participants hid their smoking to avoid social conflict (cf. Luck and Beagan, 2015), or attempted to gain a sense of independence of smoking. Downward comparisons (Vohs and Heatherton, 2004) and selfaffirmation (Derks et al., 2011; Sherman, 2013) have been reported in the psychological literature more generally as ways to cope with identity-threat. Both are considered to divert attention away from the threat, which consequently has less impact on identity. However, such strategies may be disadvantageous in the long term by decreasing the need for (healthy) behavioral change (Hoek et al., 2013).

This is the first in-depth qualitative longitudinal study into identity change dynamics in the context of smoking cessation over time. Each of ten smokers who intended to quit were interviewed three times, and data were analyzed using IPA (Smith et al., 2009). This allowed for in-depth exploration of how participants made sense of their experiences, and how this related to their sense of identity. Moreover, the longitudinal nature and close proximity of the three interviews (i.e. spaced 1 month apart) allowed direct exploration of the experience of identity during the initial processes of quitting (i.e. within the first 3 months), a particularly significant period in the quit attempt where the majority of attempts end in relapse back to smoking (Hughes et al., 2004). Limitations are that participants may have provided socially desirable answers at the online follow-up survey (e.g. stating that they were abstinent whereas in reality they smoked), and that we used no biochemical verification to assess smoking status in the follow-up survey or the interviews. However, most participants indicated that they smoked at follow-up, which reduces the need for biochemical verification. Furthermore, using biochemical verification alongside the interviews could have complicated rapport between the interviewer and participants, which would potentially have a negative effect on participants' openness and thus be inappropriate for experiential research. Social desirability may also have played a role in the experiences 
shared in the interviews and how participants presented themselves, in particular for the two participants that were already — albeit superficially — known to the first author before the study commenced. They may therefore have been more aware of their professional role or identity during the interviews, which may have given this greater prominence in their accounts. Furthermore, as is inherent to qualitative research, findings are not intended to be generalizable to the entire population of smokers intending to quit. It is also beneficial to conduct similar qualitative studies among more selective groups of smokers. For example, the facilitators of identity change that were found in Iris and Julia should be examined in a more targeted sample with successful quitters. Importantly, the experiential approach taken in this study led to valuable insights regarding identity change processes that cannot be obtained with quantitative methods. The change dynamics captured in the current study may further develop or transition over time. While the current study gains some insight of identity and smoking at 12 months, this is limited to survey data and cannot speak to identity dynamics beyond the presentation of self-descriptors, or explore incongruent statements (e.g. Karen's declared "nonsmoker identity" while not having quit successfully). Further work to interview smokers over a longer period of time would be useful, considering that a process of quitting smoking typically takes longer than 3 months. Furthermore, in accordance with the "double hermeneutic" employed in IPA (Smith et al., 2009), participants' interpretations of their experiences were interpreted by the authors and therefore the findings are shaped by the author's existing knowledge and interests (i.e. familiarity with identity theories and interest in identity change processes). Although data analysis was inductive, the authors conceptualize identity as defined in PRIME theory (West, 2006), to be "mental representations of ourselves and the feelings attached to these." Importantly, the continuous focus on grounding interpretations in the data, and discussions between the authors during the analysis, ensured that the findings closely reflected the participant accounts, and that only themes that appeared important from the participant accounts were reported. For example, participants were asked questions to explore the role of social interactions and networks in identity processes, but this was not included in the report as an additional facilitator of identity change as the participants' accounts did not point this out. As such, despite our knowledge of the importance of social factors in identity processes (e.g. Iyer et al., 2009; Lennon et al., 2005; Meijer et al., 2017; Scheffels and Lund, 2005; Tajfel and Turner, 1979, 1986; Vangeli and West, 2012), we ensured that the findings represent the participants' views and experiences.

The findings of this in-depth study indicated that change toward a nonsmoker identity may be necessary for successful quitting in the long-term. In addition, permeable identity boundaries, a continuous sense of identity, and a sense of mastery of quitting may facilitate identity change. Given these findings, future research investigating ways to help smokers to perceive themselves increasingly as nonsmokers appears warranted, for example, through writing exercises about the future identity (Meijer et al., 2018a). The findings suggest that the development of interventions with a focus on the facilitators of identity change that emerged in the current study - may help smokers to quit successfully. Specifically, smokers may be asked which "nonsmoker" characteristics they already possess, as this could facilitate perceived permeability of identity boundaries and a sense of identity continuity. In addition, in order to facilitate a "sense of mastery," which smokers may be stimulated to attribute progress in quitting internally. Such interventions that focus on identity change may help more smokers to quit successfully. 


\section{Acknowledgements}

The authors would like to thank the participants for sharing their experiences, and Mathilde Pronk for her help with transcription and initial data analysis. The authors would also like to thank three anonymous reviewers for their useful comments to improve the quality of the article.

\section{Declaration of conflicting interests}

The author(s) declared no potential conflicts of interest with respect to the research, authorship and/or publication of this article.

\section{Funding}

The author(s) disclosed receipt of the following financial support for the research, authorship, and/ or publication of this article: Funding for this study was provided by Leiden University, Department of Social and Organizational Psychology, where CVL was employed when data were collected.

\section{Supplemental material}

Supplemental material for this article is available online.

\section{ORCID iD}

Eline Meijer iD https://orcid.org/0000-0001-7078-5067

\section{References}

Bottorff JL, Johnson JL, Irwin LG, et al. (2000) Narratives of smoking relapse: The stories of postpartum women. Research in Nursing and Health 23(2): 126-134.

Brown JM (1996) Redefining smoking and the self as a nonsmoker. Western Journal of Nursing Research 18(4): 414-428.

Derks B, Scheepers D, van Laar C, et al. (2011) The threat vs. challenge of car parking for women: How self- and group affirmation affect cardiovascular responses. Journal of Experimental Social Psychology 47(1): 178-183.

Høie M, Moan IS and Rise J (2010) An extended version of the theory of planned behaviour: Prediction of intentions to quit smoking using past behaviour as moderator. Addiction Research \& Theory 18(5): 572-585.

Hertel AW and Mermelstein RJ (2016) Smoker identity development among adolescents who smoke. Psychology of Addictive Behaviors 30(4): 475-483.

Hoek J, Maubach N, Stevenson R, et al. (2013) Social smokers' management of conflicted identities. Tobacco Control 22(4): 261-265.

Hughes JR, Keely J and Naud S (2004) Shape of the relapse curve and long-term abstinence among untreated smokers. Addiction 99(1): 29-38.

Iyer A, Jetten J, Tsivrikos D, et al. (2009) The more (and the more compatible) the merrier: Multiple group memberships and identity compatibility as predictors of adjustment after life transitions. British Journal of Social Psychology 48(4): 707-733.

Kearney MH and O'Sullivan J (2003) Identity shifts as turning points in health behavior change. Western Journal of Nursing Research 25(2): 134-152.

Lennon A, Gallois C, Owen N, et al. (2005) Young women as smokers and nonsmokers: A qualitative social identity approach. Qualitative Health Research 15(10): 1345-1359.

Luck K and Beagan B (2015) Occupational transition of smoking cessation in women: "You're restructuring your whole life." Journal of Occupational Science 22(2): 183-196.

Markus H and Nurius P (1986) Possible selves. American Psychologist 41: 954-969. 
Meijer E, Gebhardt WA, Dijkstra A, et al. (2015) Quitting smoking: The importance of nonsmoker identity in predicting smoking behaviour and responses to a smoking ban. Psychology \& Health 30(12): 1387-1409.

Meijer E, Gebhardt WA, van Laar C, et al. (2016) Socio-economic status in relation to smoking: The role of (expected and desired) social support and quitter identity. Social Science \& Medicine 162: 41-49.

Meijer E, Gebhardt WA, van Laar C, et al. (2018a) Strengthening quitter self-identity: An experimental study. Psychology \& Health. Epub ahead of print 10 June. DOI: 10.1080 /08870446.2018.1478976.

Meijer E, van den Putte B, Gebhardt WA, et al. (2018b) A longitudinal study into the reciprocal effects of identities and smoking behaviour: Findings from the ITC Netherlands Survey. Social Science \& Medicine 200: 249-257.

Meijer E, van Laar C, Gebhardt WA, et al. (2017) Identity change among smokers and ex-smokers: Findings from the ITC Netherlands survey. Psychology of Addictive Behaviors 31: 465-478.

Nachtigal A and Kidron CA (2015) Existential multiplicity and the late-modern smoker: Negotiating multiple identities in a support group for smoking cessation. Sociology of Health and Illness 37(3): 452-467.

Nationaal Expertisecentrum Tabaksontmoediging (2015) Roken: een aantal feiten op een rij. Utrecht: Trimbos Instituut.

Scheffels J and Lund KE (2005) Occasional smoking in adolescence: Constructing an identity of control. Journal of Youth Studies 8(4): 445-460.

Sherman DK (2013) Self-affirmation: Understanding the effects. Social and Personality Psychology Compass 7(11): 834-845.

Smith JA (1999) Identity development during the transition to motherhood: An interpretative phenomenological analysis. Journal of Reproductive and Infant Psychology 17(3): 281-299.

Smith JA, Flowers P and Larkin M (2009) Interpretative Phenomenological Analysis: Theory, Method and Research. London: SAGE.

Smith JA, Spiers J, Simpson P, et al. (2016) The psychological challenges of living with an ileostomy: An interpretative phenomenological analysis. Health Psychology 36: 143-151.

Snelgrove S, Edwards S and Liossi C (2013) A longitudinal study of patients' experiences of chronic low back pain using interpretative phenomenological analysis: Changes and consistencies. Psychology \& Health 28(2): 121-138.

Sokol Y and Serper M (2016) Temporal self appraisal and continuous identity: Associations with depression and hopelessness. Journal of Affective Disorders 208: 503-511.

Spiers J, Smith JA and Drage M (2015) A longitudinal interpretative phenomenological analysis of the process of kidney recipients' resolution of complex ambiguities within relationships with their living donors. Journal of Health Psychology 21(11): 2600-2611.

Tajfel H and Turner JC (1979) An integrative theory of intergroup conflict. In: Austin WG and Worchel S (eds) The Social Psychology of Intergroup Relations. Monterey, CA: Brooks/Cole Publishing Company, pp. 33-47.

Tajfel H and Turner JC (1986) The social identity theory of intergroup behavior. In: Worchel S and Austin WG (eds) The Psychology of Intergroup Relations. Chicago, IL: Nelson-Hall, pp. $7-24$.

Tombor I, Shahab L, Brown J, et al. (2013) Positive smoker identity as a barrier to quitting smoking: Findings from a national survey of smokers in England. Drug and Alcohol Dependence 133(2): 740-745.

Tombor I, Shahab L, Brown J, et al. (2015) Does non-smoker identity following quitting predict long-term abstinence? Evidence from a population survey in England. Addictive Behaviors 45: $99-103$. 
U.S. Department of Health and Human Services (2014) The Health Consequences of Smoking 50 Years of Progress: A Report of the Surgeon General. Atlanta, GA: U.S. Department of Health and Human Services, Centers for Disease Control and Prevention, National Center for Chronic Disease Prevention and Health Promotion, Office on Smoking and Health.

Vangeli E and West R (2012) Transition towards a "non-smoker" identity following smoking cessation: An interpretative phenomenological analysis. British Journal of Health Psychology 17(1): 171-184.

Vohs KD and Heatherton TF (2004) Ego threat elicits different social comparison processes among high and low self-esteem people: Implications for interpersonal perceptions. Social Cognition 22(1): 168-191.

West R (2006) Theory of Addiction. Oxford: Blackwell; Addiction Press.

Wilson S, Cunningham-Burley S, Bancroft A, et al. (2007) Young people, biographical narratives and the life grid: Young people's accounts of parental substance use. Qualitative Research 7(1): 135-151.

\section{Author biographies}

Eline Meijer is senior researcher at Leiden University Medical Center, The Netherlands. She is an expert on smoking cessation, focusing on identity processes, implementation of smoking cessation care by healthcare professionals, and eHealth applications for smoking cessation. She also works as a therapist.

Eleni Vangeli is senior lecturer in Psychology at London South Bank University, United Kingdom. Her primary research focus and applied practice, as a health psychologist, is in the addiction field. She has particular expertise in the application of qualitative methods to explore identity and identity transitions following cessation (or recovery) of substance use and misuse.

Winifred A Gebhardt is associate professor of Health Psychology at Leiden University, The Netherlands. She is an expert on health behavior change, goal setting and identity. Her current research focuses on the dynamic interaction between health goals and other personal goals, as well as intervention techniques to facilitate connections between health goals and personal identity.

Colette van Laar is professor of Psychology at the Center for Social \& Cultural Psychology (CSCP) at the University of Leuven (KU Leuven) in Belgium. Her research examines social psychological factors and processes that transfer negative group stereotypes and prejudice into lower outcomes in education and work. 